\title{
Study of Efficiencies CdTe/CdS Photovoltaic Solar Cell According to Electrical Properties by Scaps Simulation
}

\author{
Serigne Massamba Seck1,2*, Elhadji Ndiouga Ndiaye³, Modou Fall², Stéphane Charvet ${ }^{1}$ \\ ${ }^{1}$ Laboratoire de Physique de la Matière Condensée (LPMC), Université de Picardie Jules Verne, Amiens, France \\ ${ }^{2}$ Laboratoire de Chimie Physique Organique et d'Analyses Environnementales (LCPOAE), Université Cheikh Anta Diop, \\ Dakar, Senegal \\ ${ }^{3}$ Département de Physique, UFR SATIC, Université Alioune Diop de Bambey, Bambey, Senegal \\ Email: *massamba.seck22@gmail.com
}

How to cite this paper: Seck, S.M., Ndiaye, E.N., Fall, M. and Charvet, S. (2020) Study of Efficiencies CdTe/CdS Photovoltaic Solar Cell According to Electrical Properties by Scaps Simulation. Natural Resources, $11,147-155$.

https://doi.org/10.4236/nr.2020.114009

Received: March 7, 2020

Accepted: April 6, 2020

Published: April 9, 2020

Copyright $\odot 2020$ by author(s) and Scientific Research Publishing Inc. This work is licensed under the Creative Commons Attribution International License (CC BY 4.0).

http://creativecommons.org/licenses/by/4.0/

\begin{abstract}
The photovoltaic performance (efficiency $\eta$ ) of an ITO/CdS/CdTe structure cell is studied in this article according to its electrical properties. The study is carried out by simulation with SCAPS (Solar Cell Capacitance Simulator) whose mathematical model is based on solving the equations of Poisson and continuity of electrons and holes. An electrical conversion efficiency of $23.58 \%$ is obtained by optimizing the mobility of the electrons $\left(100 \mathrm{~cm}^{2} / \mathrm{Vs}\right)$, that of the holes $\left(25 \mathrm{~cm}^{2} / \mathrm{Vs}\right)$, the density of electrons $\left(10^{15} \mathrm{~cm}^{-3}\right)$, the density of the effective states in the conduction band $\left(7.9 \times 10^{17} \mathrm{~cm}^{-3}\right)$ and the electronic affinity $(3.85 \mathrm{eV})$ of the CdTe absorbent layer.
\end{abstract}

\section{Keywords}

Solar Cells, Photovoltaic, Thin Films, CdTe, Electron Mobility, Charge Carrier Density, Simulation, SCAPS

\section{Introduction}

The very high solar potentials in Sahelian countries $\left(5.7 \mathrm{kWh} / \mathrm{m}^{2} /\right.$ day on the ground of solar energy) [1], do not relate the equivalent photovoltaic solar performances of the panels installed in these places. They are far lower than the powers obtained by the standard test conditions (irradiation: $1000 \mathrm{~W} \cdot \mathrm{m}^{-2}$, module temperature: $25^{\circ} \mathrm{C}$, spectral distribution of the radiation: AM 1: 5). There are many reasons, in particular the fact that very high local temperatures are not taken into account, which are environmental conditions dissimilar to those of 
the tests. A photovoltaic panel whose surface temperature exceeds 25 degrees, loses up to half a percent of efficiency per additional degree [2]

The production of photovoltaic electricity is obtained by the conversion of solar energy (solar radiation) with photovoltaic solar panels or modules made up of series/parallel assemblies of photovoltaic solar cells obtained from organic inorganic or hybrid photovoltaic materials [3] [4]. Moreover, thin-film solar cells have many advantages, in particular their ease of synthesis, their low cost in a wide range and their adaptability in industrial production. Indeed, mono-junctions of monocrystalline silicon and of polycrystalline silicon form the first solar technologies offering respectively yields going up to $21 \%$ and $14 \%$ [5].

With the development of technology and the creation of new basic materials, high yields are obtained [6]. As a result, the performance of photovoltaic modules is strongly linked to the intrinsic parameters of the basic materials constituting each element that a photovoltaic solar cell makes up (chemical nature, gap, doping rate, carrier mobility). Controlling these parameters will therefore effectively improve the performance of solar panels.

This paper presents a study by simulation of heterojunction CdTe solar cells by SCAPS simulation according to the parameters (charge carrier densities, mobilities and electronic affinities) of the components of solar cells. It links the influence of parameters on electrical performance under standard test conditions.

The use of techniques for simulating the performance of a solar cell has several advantages. It minimizes the cost of manufacturing prototypes by offering the possibility of varying all parameters. They make it possible to better understand the impact of different physical parameters on cell performance, and to design and optimize different cells without the need to systematically use experimental procedures which can prove to be expensive. Finally, they make it possible to assess the performance of a structure and its maximum theoretical yield. It also offers the opportunity to study the influence of each layer of the cell in the case of interdependent parameters.

\section{Materials and Method}

\subsection{Presentation of SCAPS (Solar Cell Capacitance Simulator)}

SCAPS allows simulation of one-dimensional solar cells [7]. SCAPS software was originally developed to model and simulate the electrical characteristics of heterojunction and thin-film photovoltaic solar cells. It has also been tested on CdTe and CIGS solar cell structures by M. Burgelman et al. [8] [9], the developers. The simulated and measured results were in good agreement with the practical cases. Moreover, several versions have improved its capacities allowing their applicability to crystalline solar cells ( $\mathrm{Si}$ and GaAs) and amorphous cells (a-Si and $\mathrm{Si}$ micro-morph) [10]. In addition, SCAPS has a database containing several types of solar cells, data file, with modifiable parameters (thickness, doping).

The equations that govern the studied model are the equations of Poisson and 
continuity for electrons and holes.

$$
\frac{\mathrm{d}^{2} \varphi}{\mathrm{d} x^{2}}=-\frac{q}{\varepsilon_{0} \varepsilon_{r}}\left(p-n-N_{A}^{-}+N_{D}^{+}+\frac{\rho_{t}}{q}\right)
$$

And:

$$
\left\{\begin{array}{l}
\frac{1}{q} \frac{\mathrm{d} J_{x}}{\mathrm{~d} x}=G-R_{n} \\
-\frac{1}{q} \frac{\mathrm{d} J_{p}}{\mathrm{~d} x}=G-R_{p}
\end{array}\right.
$$

In Equation (1) and Equation (2), $\varphi$ describes electrical potential, $q$ is the unit charge, $\varepsilon_{0}$ and $\varepsilon_{r}$ are the dielectric constants of vacuum and semiconductor, respectively; $n$ and $p$ are electron and hole density, respectively; $N_{A}^{-}$and $N_{D}^{+}$are the density of ionized donors and acceptors, $\rho_{t}$ the charge density of defects, $J_{n}$ and $J_{p}$ the electron and hole current density; $G$ is the generation rate and $R_{n(p)}$ is the recombination loss.

The transportation of carriers is shown by:

$$
\left\{\begin{array}{l}
J_{n}=-q D_{n} \frac{\mathrm{d} n}{\mathrm{~d} x}+q \mu_{n} \frac{\mathrm{d} \varphi}{\mathrm{d} x} \\
J_{p}=-q D_{p} \frac{\mathrm{d} p}{\mathrm{~d} x}-q \mu_{p} \frac{\mathrm{d} \varphi}{\mathrm{d} x}
\end{array}\right.
$$

where $\mu_{n(p)}$ is the electron/hole mobility and $D_{n(p)}$ is the diffusion coefficient.

The generation rate is given by:

$$
G(\lambda, x)=\varphi_{0}(\lambda) e^{-\alpha(\lambda) \cdot x}
$$

where $\varphi_{0}$ is the incident photon flux, $x$ is a depth and $\alpha$ the absorption coefficient of the active material and $\lambda$, the absorbed photon wave length. Cell performance was achieved with scaps under standard conditions (a cell temperature of $25^{\circ} \mathrm{C}$ and radiation of $1000 \mathrm{~W} / \mathrm{m}^{2}$ with an air mass spectrum of 1.5 (AM1.5)).

\subsection{Methodological Approach}

We aim to optimize the efficiency of our solar cell by modifying the characteristics (mobility, doping) of CdTe with SCAPS. It makes it possible to study and analyze the evolution of characteristics such as Jsc, Voc, FF and therefore the efficiency $\eta$ as a function of the intrinsic properties of doped CdTe.

The recommended method for introducing a solar cell is to use the graphical interface of SCAPS. In this way, we can interactively introduce all the parameters that will be controlled by SCAPS so as not to have impossible or inconsistent values [7].

\subsection{Properties and Structure of Studied CdTe Solar Cell}

We used a thin film solar cell in ITO/CdS/CdTe structure, where CdTe the base layer, CdS the emitter and ITO the antireflecting layer. The front contact is made of aluminum. All the thicknesses of ITO, CdS and CdTe layer were respectively $0.30,0.08$ and $4.00 \mu \mathrm{m}$. The parameters of the materials used in this modeling 
were selected from experimental data in the literature and from the characteristic values (see Table 1) [7] [10] [11].

\section{Results and Discussions}

\subsection{J-V Characteristic of the CdTe Solar Cell}

With the data, we can save the variations of Jsc, Voc, FF and analyze the efficiency $\eta$. the J-V characteristic modeled in Figure 1 uses the values in Table 1.

The efficiency of the CdTe/CdS solar cell reached $21.34 \%$ similar to that of a practical CdTe based solar cell [11]. This proves that our solar cell model is valid and can be used to perform a simulation analysis of its performance with different parameters of the material. Then, we look for the effect of the evolution of the electrical characteristics (Jsc, Voc, FF and $\eta$ ) as a function of the intrinsic properties of the material (doping, mobility) in order to optimize them and predict their behavior of the photocell.

\subsection{Effect of the Mobility of CdTe Charge Carriers on Yield}

The efficiency $(\eta)$ is analyzed as a function of the electrons and holes mobility (Figure 2). The efficiency of the cell decreases with the increase in mobility of the electrons (Figure 2(A)) and increases with the speed of the holes (Figure 2(B)). These results are in agreement with those of the literature. Because a couple of mobility of the charge carriers which is not optimized adds constraints on the thickness of the active layer and increases the losses by recombinations [12].

The conversion efficiency is evaluated based on carrier mobility couples. The yield is maximal and equal to $22.10 \%$ for a couple of mobility equal to 100 $\mathrm{cm}^{2} / \mathrm{Vs}$ for electrons and $25 \mathrm{~cm}^{2} / \mathrm{Vs}$ to that of the holes (Table 2).

Table 1. Used characteristic values on SCAPS.

\begin{tabular}{cccc}
\hline Parameters & \multicolumn{3}{c}{ Layers } \\
\cline { 2 - 4 } & ITO & CdS & CdTe \\
\hline Permittivity & 9.0 & 10.0 & 10.2 \\
Effective state density in the BC $\left(\mathrm{cm}^{-3}\right)$ & $2.20 \times 10^{+18}$ & $2.20 \times 10^{+18}$ & $8.0 \times 10^{+17}$ \\
Effective density of states in BV $\left(\mathrm{cm}^{-3}\right)$ & $1.80 \times 10^{+19}$ & $1.80 \times 10^{+19}$ & $1.80 \times 10^{+19}$ \\
Electrons mobility $\left(\mathrm{cm}^{2} / \mathrm{Vs}\right)$ & $1.0 \times 10^{+2}$ & $1.0 \times 10^{+2}$ & $3.2 \times 10^{+2}$ \\
Holes mobility $\left(\mathrm{cm}^{2} / \mathrm{Vs}\right)$ & $2.5 \times 10^{+1}$ & $2.5 \times 10^{+1}$ & $4.0 \times 10^{+1}$ \\
Donor density Nd $\left(\mathrm{cm}^{-3}\right)$ & $1.0 \times 10^{+17}$ & $1.0 \times 10^{+17}$ & 0.0 \\
Acceptor density Na $\left(\mathrm{cm}^{-3}\right)$ & 0.0 & 0.0 & $1.0 \times 10^{+14}$ \\
Absorption coefficient $\left(\mathrm{cm}^{-1}\right)$ & $1.0 \times 10^{+6}$ & $\mathrm{SCAPS}$ & $1.0 \times 10^{+5}$ \\
\hline
\end{tabular}

Table 2. Performance with different mobilities of charge carriers.

\begin{tabular}{ccccc}
\hline Electron Mobility $\left(\mathrm{cm}^{2} / \mathrm{Vs}\right)$ & 100 & 100 & 320 & 700 \\
Holes Mobility (cm $/ \mathrm{Vs})$ & 20 & 25 & 40 & 65 \\
$\eta(\%)$ & $\mathbf{2 2 . 0 3}$ & $\mathbf{2 2 . 1 0}$ & $\mathbf{2 1 . 3 4}$ & $\mathbf{2 0 . 8 2}$ \\
\hline
\end{tabular}




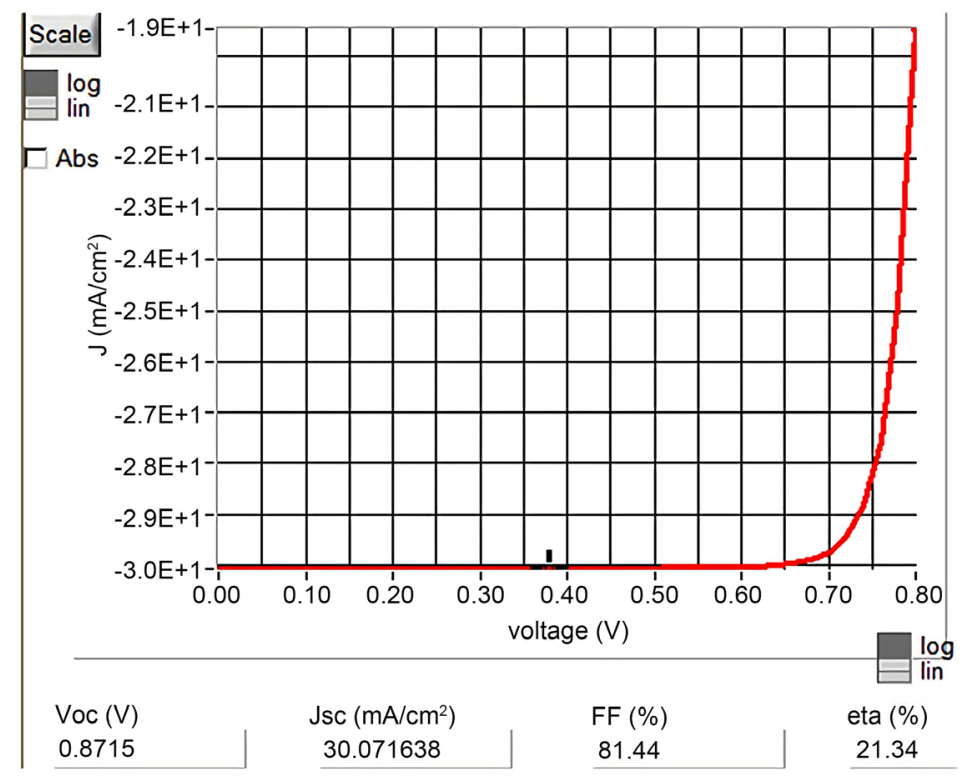

Figure 1. J-V characteristic of the modeled CdTe solar cell.
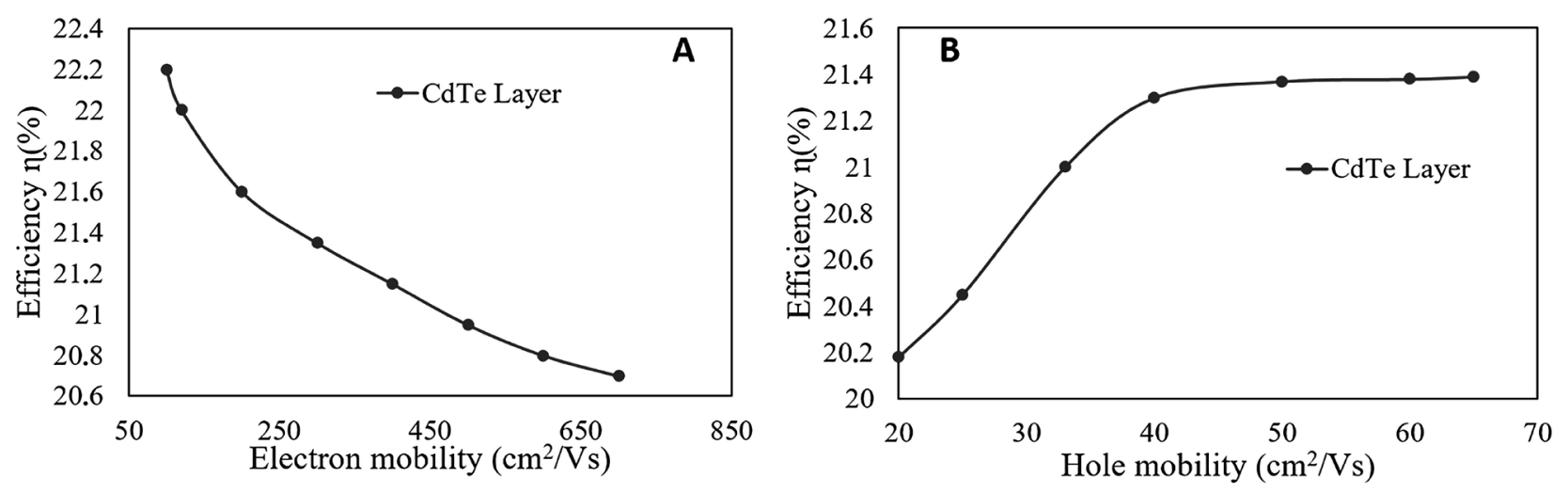

Figure 2. Variation in yield as a function of mobility (A): electrons and (B): holes in the CdTe layer.

We found that the optimum torque value of carrier mobility is required to obtain maximum efficiency of the cell.

\subsection{Effect of Carrier Density (for Acceptor) of CdTe}

The acceptor density was varied from $10^{12} \mathrm{~cm}^{-3}$ to $10^{19} \mathrm{~cm}^{-3}$ in steps of $10 \mathrm{~cm}^{-3}$. The decrease in the acceptor density of CdTe greatly reduces the yield (Figure 3). Recombination becomes important with an increase in the density of carriers. Therefore, an increase in density can drop the collection of free electrons generated by the incident radiation on front contact and contribute to lowering the value of Jsc [13]. In our conditions, a density of $10^{16} \mathrm{~cm}^{-3}$ is the optimum value which would increase the yield.

\subsection{Effect of the Density of Effective States in the BC of the CdTe Layer on the Yield}

The density of the effective states was varied from $7.9 \times 10^{17} \mathrm{~cm}^{-3}$ to $22 \times 10^{17} \mathrm{~cm}^{-3}$. 
An effective state density in the smaller conduction band (CB) gives the best performance [14]. The more the density of the effective states in the CB increases the more the efficiency of the cell decreases (Figure 4). A density of $7.9 \times 10^{17}$ $\mathrm{cm}^{-3}$ is the best value.

\subsection{Effect of the Electronic Affinity of the CdTe Layer on the PV Conversion Efficiency}

A low electronic affinity of the CdTe absorber indicates a low efficiency from 3.8 $\mathrm{eV}$. For an electronic affinity between $3.8 \mathrm{eV}$ and $3.85 \mathrm{eV}$, the efficiency equal to $21.37 \%$ is maximum and almost constant throughout the range before decreasing after $3.85 \mathrm{eV}$ (Figure 5).

The results obtained are consistent because the differences in electronic affinities and band gap energies cause a discontinuity at the level of the connection of the conduction and valence bands. Therefore, the influence of the electronic affinity of the CdTe layer $\left(\mathrm{CdTe}_{\text {gap }}=1.45 \mathrm{eV}\right.$ vs $\left.\mathrm{CdS}_{\text {gap }}=2.5 \mathrm{eV}\right)$ in the solar cell, acts on the energy difference in the conduction band.

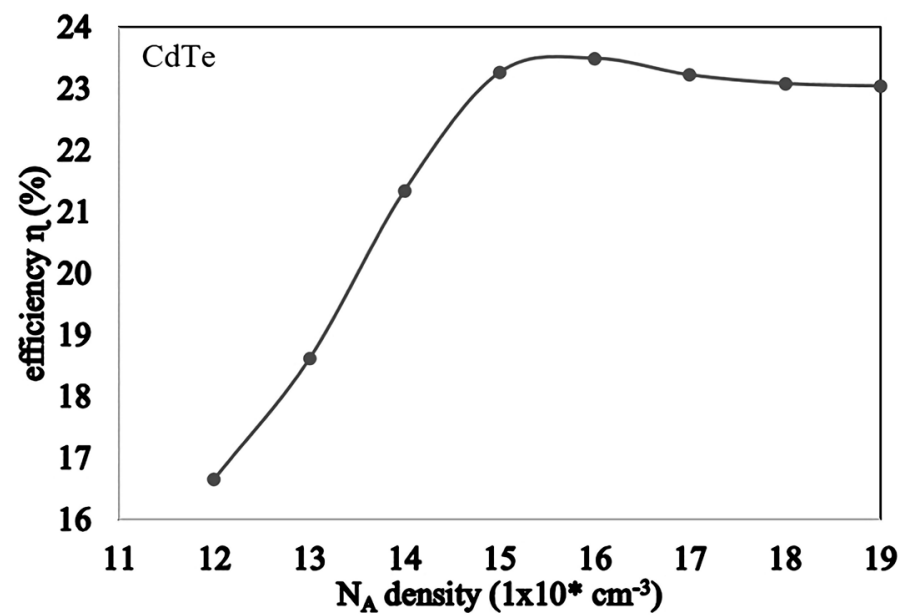

Figure 3. Yield as a function of the density of carriers (acceptor) of CdTe.

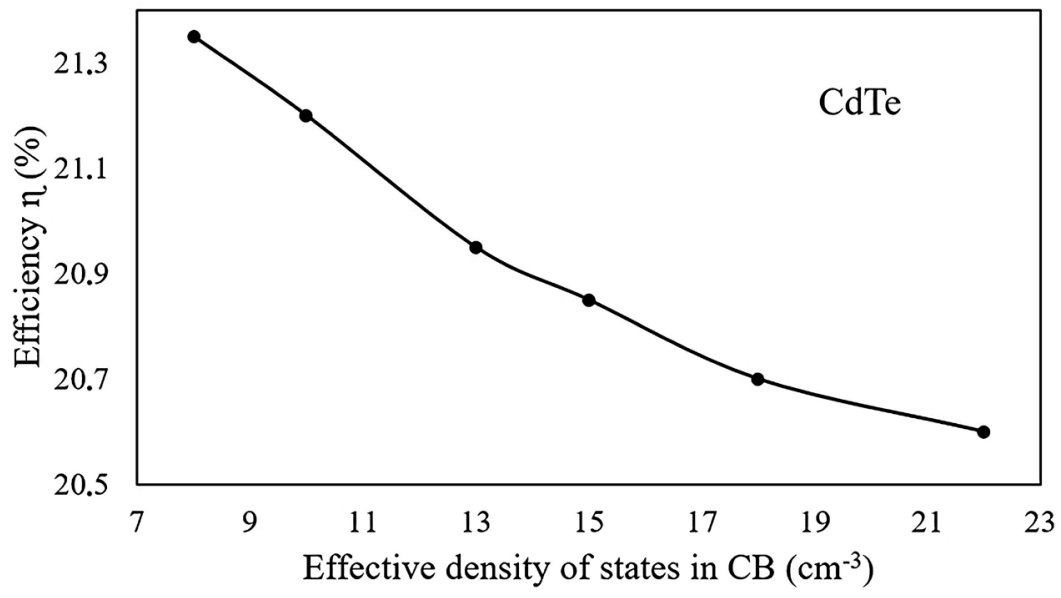

Figure 4. Efficiency as a function of the effective state density in the CB of CdTe. 


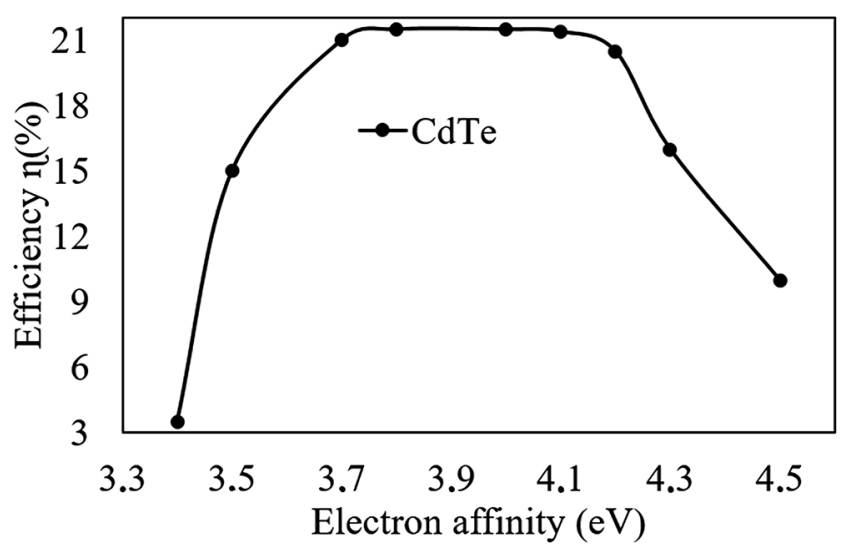

Figure 5. Yield based on the CdTe layer of electron affinity.

However, for CdS/CdTe cell, the values of $\Delta \mathrm{Ec}\left(\chi_{\mathrm{CdS}}-\chi_{\mathrm{CdTe}}\right)$ lie between 0.20 and $0.25 \mathrm{eV}$ and are found to be independent of the process of cell fabrication [15].

\section{Conclusions}

This work established an analysis of the relationship between the properties of the layers of the ITO/CdS/CdTe structure cell and their performance with an optimal electrical conversion efficiency of $23.58 \%$.

In fact, the optimized values are:

- A couple of mobility of charge carriers of the CdTe layer (mobility of the electrons of $100 \mathrm{~cm}^{2} / \mathrm{Vs}$ and that of the holes of $25 \mathrm{~cm}^{2} / \mathrm{Vs}$ ).

- A density of the electrons in the CdTe absorbent layer which allows us to obtain coherent results and a good yield of $10^{15} \mathrm{~cm}^{-3}$.

- A density of the effective states in the conduction band in the absorbent layer CdTe of $7.910^{17} \mathrm{~cm}^{-3}$.

- A reasonable and acceptable dielectric permittivity of the absorber layer CdTe of 8.

- An electronic affinity of the absorber layer $\mathrm{CdTe}=3.85 \mathrm{eV}$.

However, the increase in the optical gap of the CdTe absorber layer reduces the intensity of the photocurrent while the open circuit voltage increases. The compromise between these two phenomena gives an optimum value of the optical gap EgCdTeopt $=1.47 \mathrm{eV}$ which corresponds to the maximum efficiency of the cell.

Thus, we were able to show the impact of the studied characteristics (charge carriers mobility, the density of carriers, the density of effective states, the dielectric permittivity and the electronic affinity) on the efficiency of the solar cell with SCAPS. The results of simulation of the thin film solar cell based on CdTe, are in good agreement with those of the literature, which show that the parameters of the photovoltaic cell have significant effects on the photovoltaic performances (Voc, Jsc, FF and $\eta$ ).

Therefore, we can say that the main factors limiting photovoltaic performance 
in African ecosystems, linked to the physical properties of materials, can be circumvented by also taking temperatures into account.

\section{Acknowledgements}

We would like to thank all the members of the physical department of Alioune Diop University in Bambey Senegal for the collaboration with the interuniversity master of renewable energies (MIER) and Professor M. Burgelman and colleagues for develop SCAPS available to us (ulis.be).

\section{Conflicts of Interest}

The authors declare no conflicts of interest regarding the publication of this paper.

\section{References}

[1] Ould Bilal, B., Sambou, V., Kebé, C.M.F., Ndongo, M. and Ndiaye, P.A. (2007) Etude et modélisation du potentiel solaire du site de nouakchott et de dakar. Journal des Sciences, 7, 57-66.

[2] Equer, B. (1993) Physique et technologie de la conversion photovoltaïque. ELLIPES, Paris.

[3] Chamberlain, G.A. (1983) Organic Solar Cells: A Review. Solar Cells, 8, 47-83. https://doi.org/10.1016/0379-6787(83)90039-X

[4] Wright, M. and Uddin, A. (2012) Organic-Inorganic Hybrid Solar Cells: A Comparative Review. Solar Energy Materials and Solar Cells, 107, 87-111. https://doi.org/10.1016/j.solmat.2012.07.006

[5] Bruton, T., Mason, N., Roberts, S., Hartley, O.N., Gledhill, S., Fernandez, J., Russell, R., Warta, W., Glunz, S., Schultz, O., Hermle, M. and Willeke, G. (2003) Towards 20\% Efficient Silicon Solar Cells Manufactured at $60 \mathrm{MWp}$ per Annum.

[6] Slaoui, A. (2015) Matériaux et Technologie pour le photovoltaïque: Etat de l'Art et Perspectives. CNRS.

[7] Burgelman, M., Decock, K., Niemegeers, A., Verschraegen, J. and Degrave, S. (2019) SCAPS Manual. Elis-Ugent, December.

[8] Burgelman, M., Nollet, P. and Degrave, S. (2000) Modelling Polycrystalline Semiconductor Solar Cells. Thin Solid Films, 361, 527-532.

https://doi.org/10.1016/S0040-6090(99)00825-1

[9] Burgelman, M., Verschraegen, J., Degrave, S. and Nollet, P. (2004) Modeling Thin-Film PV Devices. Progress in Photovoltaics. Research and Applications, 12 143-153. https://doi.org/10.1002/pip.524

[10] elis.ugent.be (2019) http://scaps.elis.ugent.be/

[11] Kai, S., Li, Q., Wang, D.Z., Yang, R.L., Deng, Y., Jeng, M.-J. and Wang, D.L. (2016) CdTe Solar Cell Performance under Low-Intensity Light Irradiance. Solar Energy Materials \& Solar Cells, 144, 472-480. https://doi.org/10.1016/j.solmat.2015.09.043

[12] Hacène, B. (2014) Modélisation et simulation des cellules solaires à base de P3HT: PCBM (effet de la mobilite et la vitesse de recombinaison en surface). Universite Abu BakrBekkaid, Algerie.

[13] Hervé, J., Tchognia, N., Hartiti, B., Ndjaka, J.-M. and Ridah, A. (2015) Perfor- 
mances des cellules solaires à base de $\mathrm{Cu} 2 \mathrm{ZnSnS4}$ (CZTS): Une analyse par simulations numériques via le simulateur SCAPS. Afrique Sciences, 11, 16-23.

[14] Huang, C.-H. and Chuang, W.-J. (2015) Dependence of Performance Parameters of CdTe Solar Cells on Semiconductor Properties Studied by Using SCAPS-1D. Vaccum, 118, 32-37. https://doi.org/10.1016/j.vacuum.2015.03.008

[15] Al Kuhaimi, S.A., Shaalan, N.M. and Bahammam, S (1998) The Electron Affinity Difference in CdS/CdTe Solar Cells. Proceedings of the Indian Academy of Sciences-Chemical Sciences, 110, 199-206. 